Article

\title{
Design of a Homogenizing System for Bio-degradable Food Waste from Eatery Centres
}

\author{
Olumide Babarinsa ${ }^{1}$, Emmanuel O.B. Ogedengbe ${ }^{1, *}$ and Marc A. Rosen ${ }^{2}$ \\ ${ }^{1}$ Energhx Research Group, Department of Mechanical Engineering, 353 Faculty of Engineering, \\ University of Lagos, Akoka-Yaba, Lagos, 101017, Nigeria \\ ${ }^{2}$ Faculty of Engineering and Applied Science, University of Ontario Institute of Technology, \\ 2000 Simcoe Street North, Oshawa, ON, L1H 7K4, Canada \\ E-Mails: ogedengbe@energhx.com (E. O. B. O.); olumide.babarinsa@energhx.com (O. B.); \\ marc.rosen@uoit.ca (M. A. R.) \\ * Author to whom correspondence should be addressed; Tel.: +234-703-668-9827; E-Mail: \\ ogedengbe@energhx.com (E. O. B. O.)
}

Received: 07 August 2013/Accepted: 27 October 2013 / Published: 01 November 2013

\begin{abstract}
Effective pre-treatment of food waste is important to ensure that subsequent treatment in a biogas plant works well. This paper describes a two-dimensional finite volume model for the design of a homogenizing system for bio-degradable food waste from eatery centers. The numerical solver incorporates the analysis of the property distribution for food waste slurry in a storage tank, while coupling the impact of mixing on the slurry fluid. The partial differential equations which describe the conservation of mass, momentum and energy are simulated. The simulation covers the mixing and heating cycles of the slurry. The slurry fluid is exposed to a pretreatment temperature of $60^{\circ} \mathrm{C}$. With carrot-orange soup as the studied food waste, constant density and a temperature dependent viscosity are assumed. The predicted results for velocity, pressure and temperature distribution are discussed and a source term for mixing is proposed.
\end{abstract}


This assessment of distribution of velocity and temperature is expected play a role in future studies and designs of a homogenizer for biodegradable food waste.

Keywords: homogenizer; finite volume modelling; bio-digester.

\section{Introduction}

Food waste is the second largest category of municipal solid waste sent to landfills in the United States, accounting for approximately $18 \%$ of the waste stream. Among other sources of biomass, this bio-degradable feedstock consists of food scraps from restaurants, produce markets, fish markets, school cafeterias, homes and wherever else food is prepared. Typical food waste is in solid form, containing 80-90\% moisture; this implies that treatment such as incineration cannot be applied [1]. However, dumping of food waste in landfills generates methane, a potent greenhouse gas. Consequently, many research efforts have been devoted to the treatment of food waste in order to explore the possibilities of energy recovery from such feedstock, and to prevent its adverse environmental effects.

Anaerobic digestion of biodegradable food waste is the most common approach, and offers the most cost effective treatment, due to its high energy recovery and low environmental impact [2]. For sludge stabilization, this process helps with the co-digestion of sewage, leading to benefits like dilution of potential toxic compounds, improved balance of nutrients, synergistic effects regarding microorganisms, increased load of biodegradable organic matter and improved yield [3]. In a separate study conducted by the East Bay Municipal Utility District, it was revealed that food waste has up to three times as much energy potential as bio solids. As energy prices continue to rise and countries seek renewable energy generation and energy independence, exploiting the energy from food waste is expected to become increasingly important.

Effective pre-treatment of food waste is important to the performance of a biogas plant. This treatment starts with the collection of the bio-degradable food waste from eatery centers for sequential discharge into the homogenizer, by the use of a macerator pump (see Fig. 1). In the homogenizer, the food waste is conditioned into slurry, and held for a maximum of two weeks 
before it is transferred into the anaerobic digester. Apart from the production of slurry, the agitating and stirring effects of the homogenizer prevent sedimentation of the food waste.

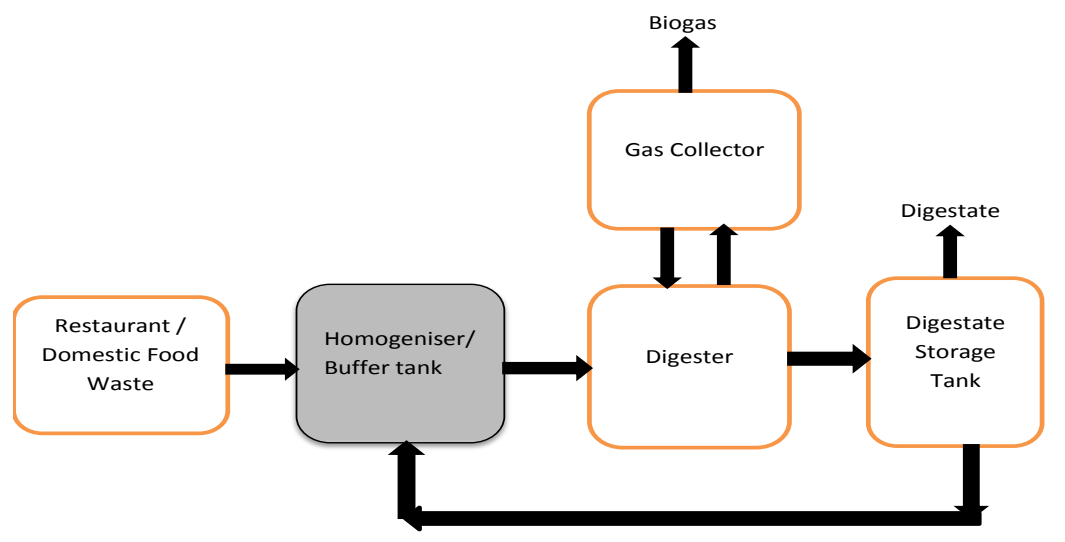

Figure 1. Process flow diagram for Food waste digestion

In a continuous processing system, digesters are equipped with a preparation tank where various substrates are mixed and prepared for loading [1]. The feedstock production, storage and supply are important part of the bio-mass to bio-energy conversion chain [4]. In an organic waste biodegradability test, Gibson et al [5] homogenized a waste mixture (85\% food waste) with a mechanical mixer for two and a half hours at $60^{\circ} \mathrm{C}$ before it was subjected to pasteurization and thermal hydrolysis. Wang et al [6] also exposed food waste meant for digestion to two types of thermal pre-treatment : $70^{\circ} \mathrm{C}$ for two hours or $150^{\circ} \mathrm{C}$ for one hour. An efficient storage tank or holding tank is required to ensure food waste is properly pre-conditioned. Apart from the existence of other pre-conditioning treatments, the mixing process is significant to the performance of an homogenizer.

Several reports in the literature apply various approaches in simulating the mixing of fluids in tanks and vessels. Harvey and Greaves [7] propose the impeller boundary condition approach, which depends on experimental data. Further improvements have been contributed by other investigators, including the use of the multiple rotating frame approach which requires a longer time for convergence [8], and the sliding mesh approach which uses large computational resources [9]. Irrespective of the size of computational resources demanded, the numerical treatment of the momentum source term approach [10], which incorporates the mixing or stirring 
effect in the momentum transports within the computational domain, represents the significant portion of the tasks in the design of an homogenizer.

This paper aims to develop the mixing or stirring source model that couples perfectly within a two-dimensional finite volume formulation of the velocity and temperature distribution. A parametric analysis of the effects of different configurations of the stirrer is performed to provide insights for the design of the homogenizer.

\section{Methodology and Numerical Simulation}

\subsection{Governing Equations}

The basic equations that govern the mathematical modeling of flow processes are the mass, momentum and energy conservation equations. The pumping process of the moisture-rich food waste through the combination of the macerator pump and a water dilute line enables the input of liquid food, assumed as an incompressible, Newtonian fluid. Using the following twodimensional, transient Navier-Stokes equations with body force and source term, we can write the following:

Continuity Equation

$$
\frac{\partial \rho}{\partial t}+\frac{\partial(\rho u)}{\partial x}+\frac{\partial(\rho v)}{\partial y}=0
$$

Momentum Equation

$$
\begin{aligned}
& \rho\left(\frac{\partial u}{\partial t}+u \frac{\partial u}{\partial x}+v \frac{\partial u}{\partial y}\right)=-\frac{\partial p}{\partial x}+\frac{\partial}{\partial x}\left(\mu \frac{\partial u}{\partial x}\right)+\frac{\partial}{\partial y}\left(\mu \frac{\partial u}{\partial y}\right)+F \\
& \rho\left(\frac{\partial v}{\partial t}+u \frac{\partial v}{\partial x}+v \frac{\partial v}{\partial y}\right)=-\frac{\partial p}{\partial y}+\frac{\partial}{\partial x}\left(\mu \frac{\partial v}{\partial x}\right)+\frac{\partial}{\partial y}\left(\mu \frac{\partial v}{\partial y}\right)+\rho g+F
\end{aligned}
$$


$\frac{\partial T}{\partial t}+u \frac{\partial T}{\partial x}+v \frac{\partial T}{\partial y}=\frac{k}{\rho c}\left[\frac{\partial}{\partial x}\left(\frac{\partial T}{\partial x}\right)+\frac{\partial}{\partial y}\left(\frac{\partial T}{\partial y}\right)\right]$

where

$\mathrm{t}$ denotes time, $\mathrm{u}$ and $\mathrm{v}$ the fluid velocities, $\mathrm{k}$ the thermal conductivity of the fluid, $\mathrm{g}$ the acceleration due to gravity, $\rho$ the density of the fluid and $c$, the specific heat capacity of the fluid.

The source term F in Eqns. (2) and (3) is derived from the force impact of the impeller on the fluid. This force is equal to the product of the mass flow rate across the interaction section and the fluid velocity variation around the blade [11]. The substantial fluid velocity variation around the blade is equal to the resultant velocity from the interaction of the fluid and the impeller blade. Mathematically, we can write

$F=\rho V^{2} A$

where

$V^{2}=(w r)^{2}-u^{2}$

and $\mathrm{w}$ is the rotational speed for the impeller (in $\mathrm{rad} / \mathrm{s}$ ), $\mathrm{r}$ is the radius of the impeller and $\mathrm{A}$ is the blade surface area. This analogy assumes that the frictional force due to the impeller action on the fluid is negligible.

\subsection{Formulation with Dirichlet Boundary Conditions}

Equations 1-6 are formulated using a two-dimensional finite volume computation domain. Figure 2 shows the control volumes for a typical staggered grid discretization of the domain. Using the SIMPLEC algorithm [12-13], Ogedengbe et al [14] proposed a NISUS-based multiple upsteam nodes for convective interpolation. Since the detailed implementation of this formulation is covered elsewhere [Ref. 14], the imposition of the Dirichlect boundary conditions is focussed on here. It is assumed that fluid velocity and temperature at all fluid-solid boundaries are equal to the corresponding values for the solid boundary. The boundary conditions used are $\mathrm{T}=\mathrm{T}_{\mathrm{w}}=333$ 
$\mathrm{K}$, and $\mathrm{u}=0$ and $\mathrm{v}=0$ at the top surface, bottom surface and side walls. The initial conditions used are $\mathrm{T}=\mathrm{T}_{\text {ref }}=301 \mathrm{~K}, \mathrm{u}=0$ and $\mathrm{v}=0$. The model liquid is taken to have constant properties except that its viscosity varies with temperature.

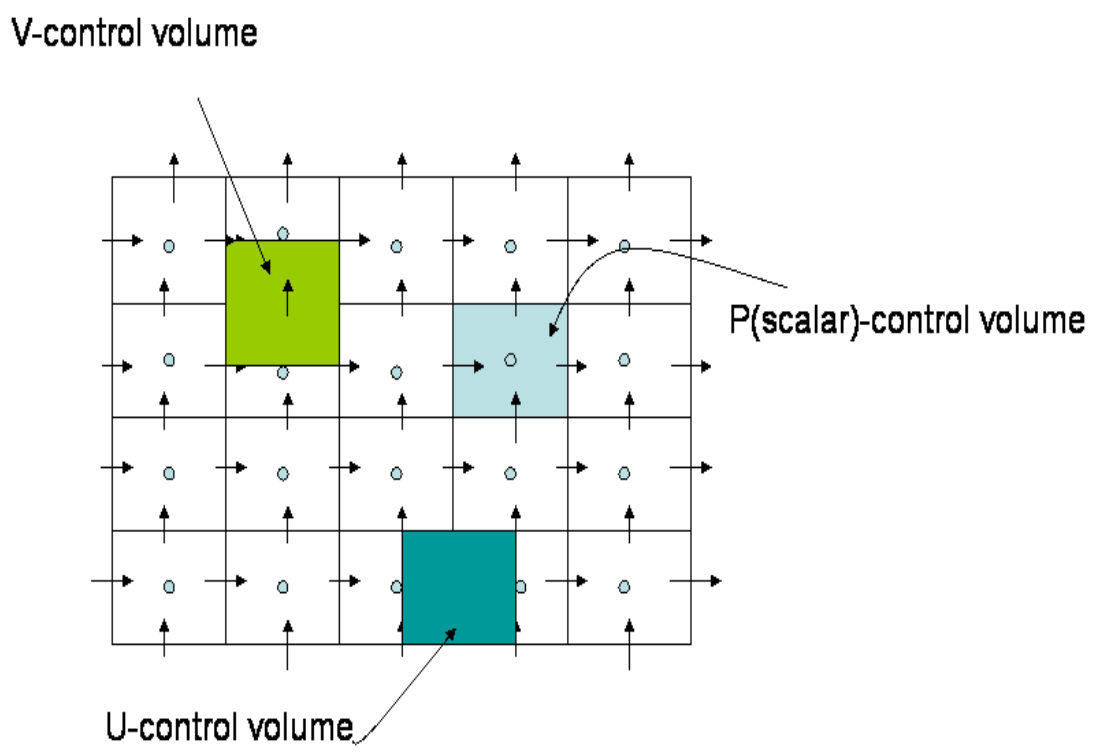

Figure 2. A typical staggered finite volume computational domain

\subsection{Numerical Simulation}

The geometry of the simulated tank is shown in Fig. 3. The homogenizer is modelled with a twodimensional rectangular domain, and a centered vertical-axis impeller. The diameter of the cylindrical vessel $(\mathrm{B})$ is $0.30 \mathrm{~m}$, while the height of the vessel $(\mathrm{H})$ is $0.375 \mathrm{~m}$. Numerical simulations are conducted at four rotational speeds of the impeller, i.e., 50, 150, 250 and 350 $\mathrm{rpm}$. The properties of carrot orange soup used in the simulation are [11]:

- $\operatorname{Density~}(\rho)=1026 \mathrm{~kg} \mathrm{~m}^{-3}$

- $\quad$ Specific heat capacity (c) $=3880 \mathrm{~J} \mathrm{~kg}^{-1} \mathrm{~K}^{-1}$

- Thermal conductivity $(\mathrm{k})=0.596 \mathrm{~W} \mathrm{~m}^{-1} \mathrm{~K}^{-1}$ 


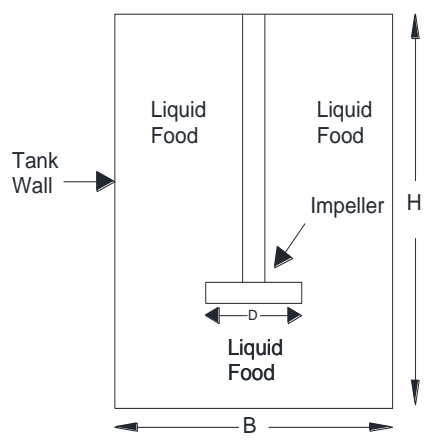

Figure 3. Sketch of the 2D model of the storage tank with impeller.

Ordinarily, food waste materials are non-Newtonian, and hence the viscosity is a function of shear rate and temperature with a flow behavior index typically less than one. However, during forced convection heating, the shear rate is small and hence the viscosity may be assumed a function of temperature only [15]. Because of the low shear rate of a liquid food used in the simulation, the viscosity can be assumed independent of shear rate so that the fluid behaves as a Newtonian fluid. In the simulation presented here, it is assumed that the viscosity can be calculated as a function of temperature:

$\mu=a+b T+c T^{2}$

where the coefficients are reported to be $1.47 \mathrm{~Pa}$. s, $-4.21 \times 10^{-2} \mathrm{~Pa} \mathrm{~s} \mathrm{~K}^{-1}$ and $3.15 \times 10^{-4} \mathrm{~Pa} \mathrm{~s} \mathrm{~K}^{-2}$, respectively.

\section{Results and Discussion}

The simulation is carried out for 40,000 iterations using a time step of $5 \times 10^{-5}$ s. Figures 4, 5, 6 and 7 show the velocity field distribution. A minimal difference can be seen in the two dimensional flow velocities obtained for the different angular velocities. With an increase in rotational speed, the velocity becomes high and the areas of the high velocity region increase. Figures 8, 9, 10 and 11 show velocity vectors at various rotational speeds. It can be seen that the momentum source increases the fluid velocity and the flow gradients. This increase can be seen in the mid-upper and lower sections of the domain. The fluid flows away from the wall, slightly 
directed towards the center and declines rapidly towards the corners of the wall. However, due to the non-linear effect of the source term (see Eqn. 5) on the velocity distribution, additional parametric experiments are required in order to establish a grid-independent impeller position on the computational domain.

U - Velocity

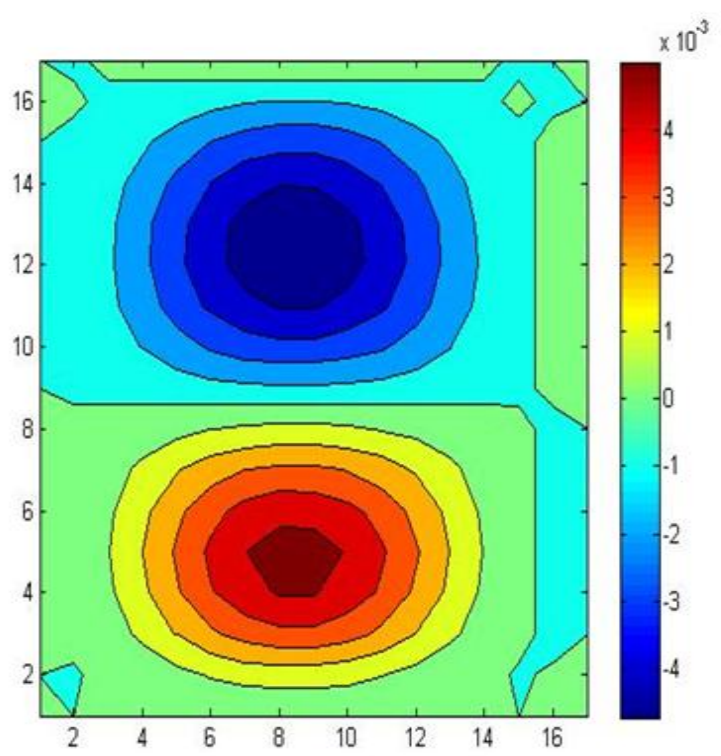

V - Velocity

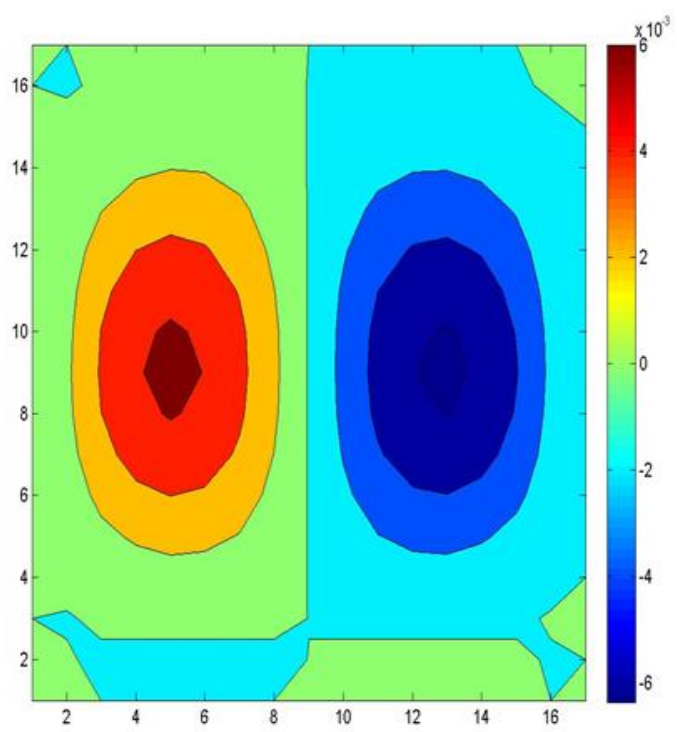

Figure 4. Two dimensional flow velocity contours, in $\mathrm{m} / \mathrm{s}$, coloured by velocity magnitude for an impeller speed of $50 \mathrm{RPM}$
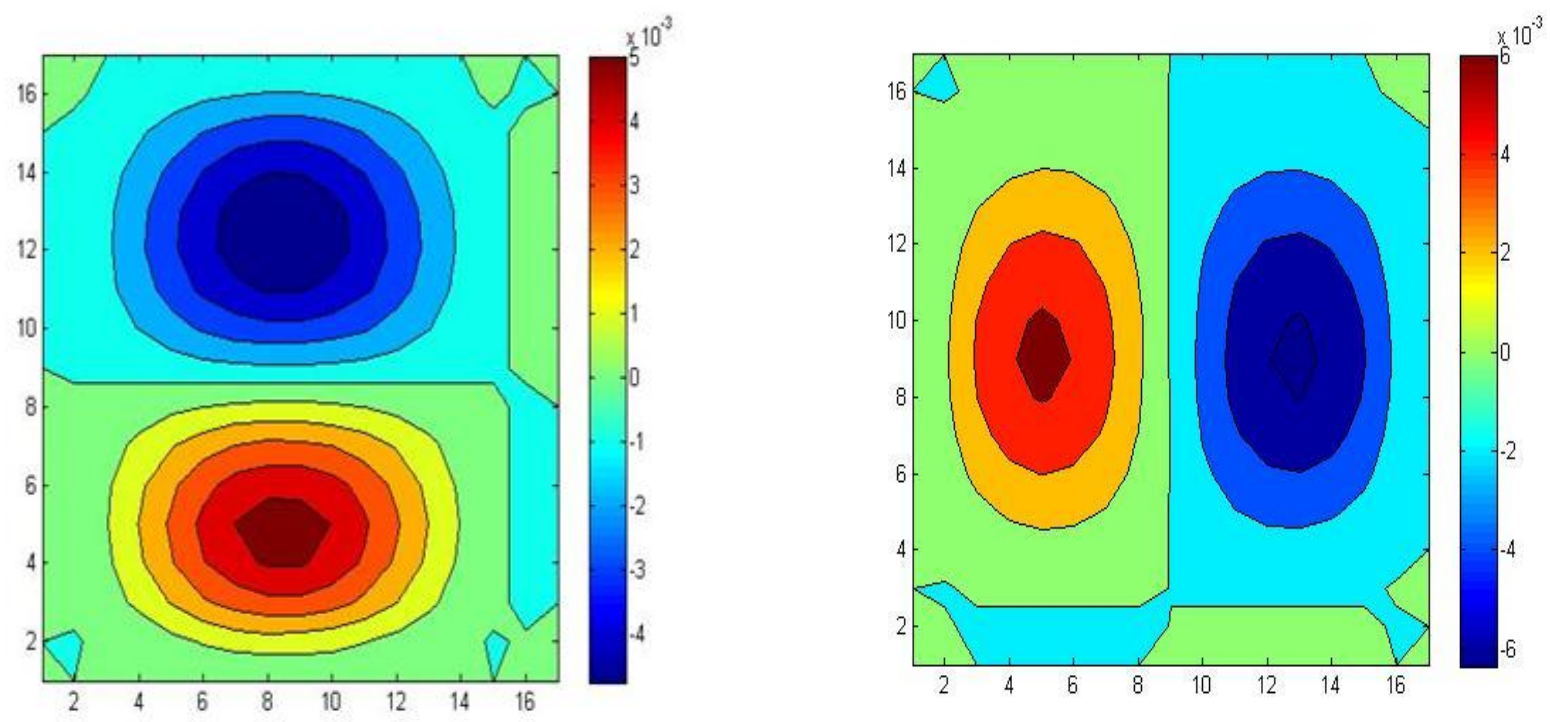

Figure 5. Two dimensional flow velocity contours, in $\mathrm{m} / \mathrm{s}$, coloured by velocity magnitude for an impeller speed of 150 RPM 

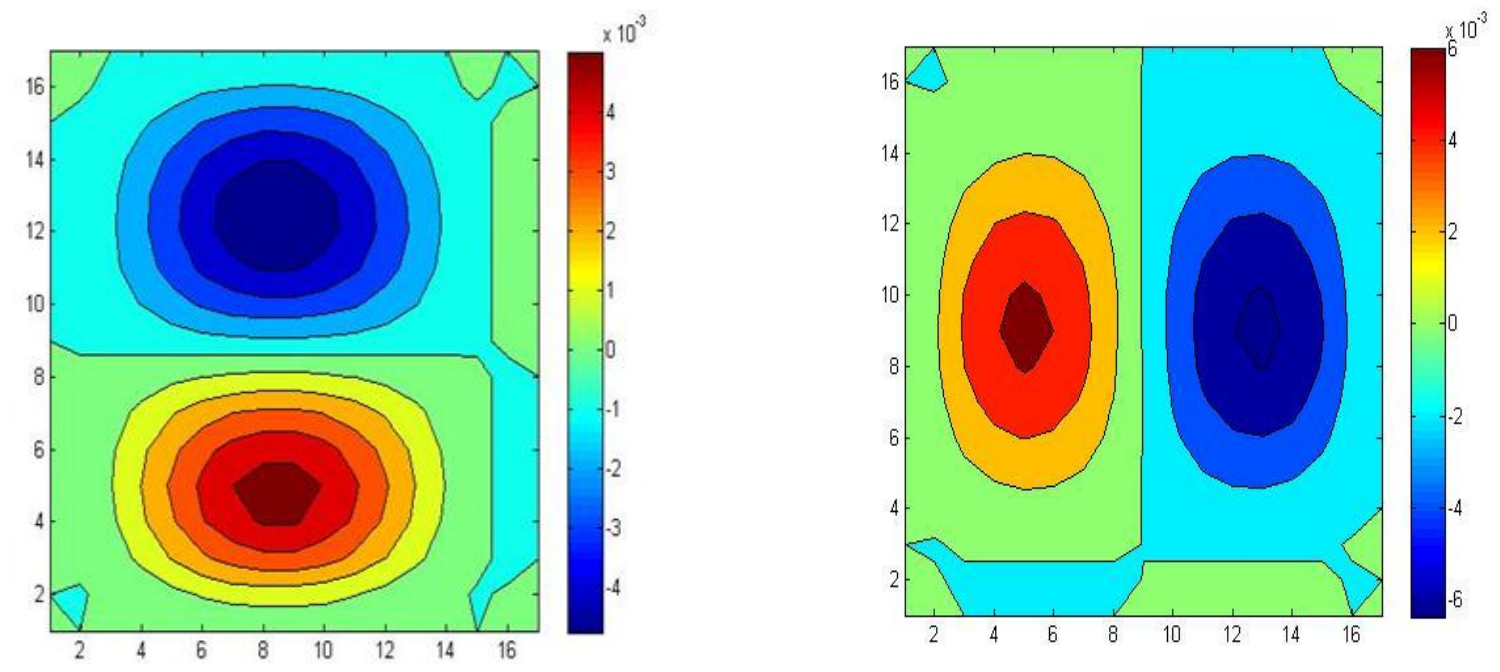

Figure 6. Two dimensional flow velocity contours, in $\mathrm{m} / \mathrm{s}$, coloured by velocity magnitude for an impeller speed of $250 \mathrm{RPM}$
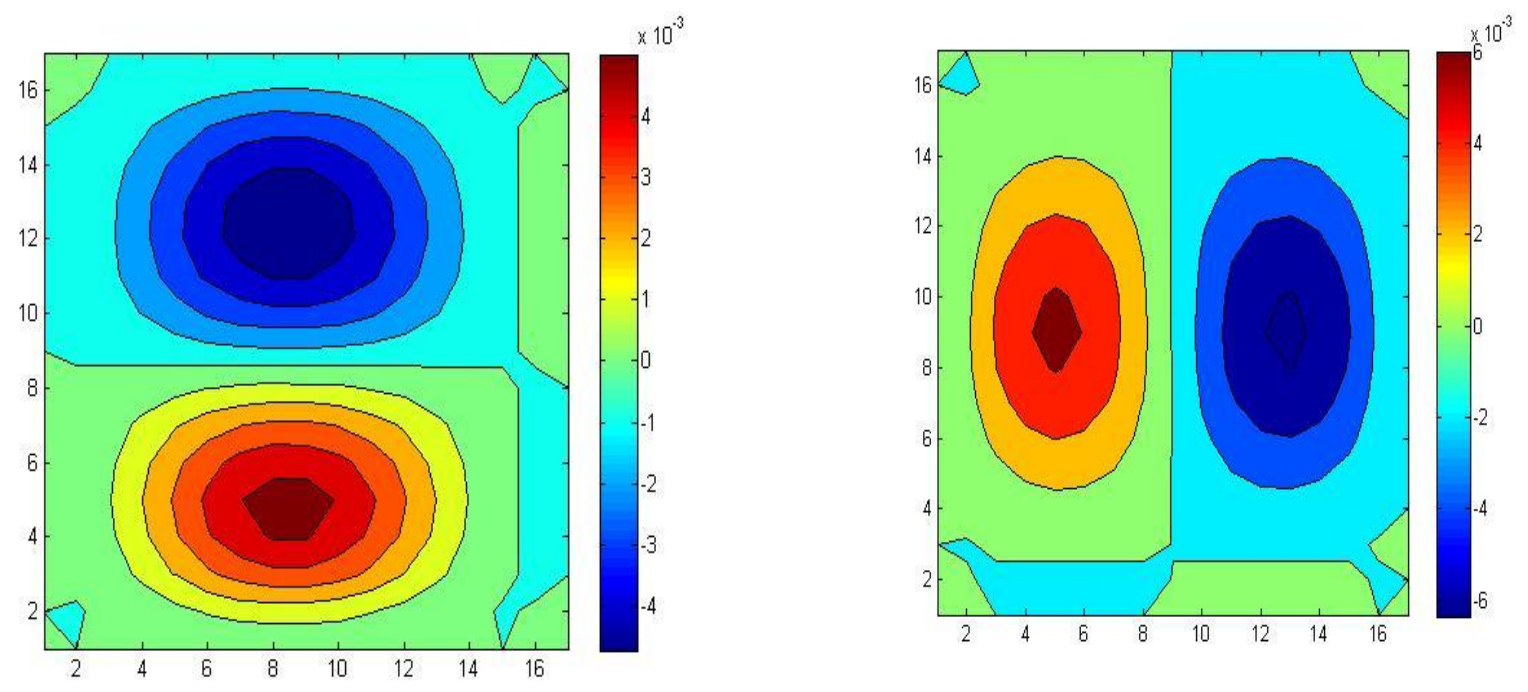

Figure 7. Two dimensional flow velocity contours, in $\mathrm{m} / \mathrm{s}$, coloured by velocity magnitude for an impeller speed of $350 \mathrm{RPM}$ 


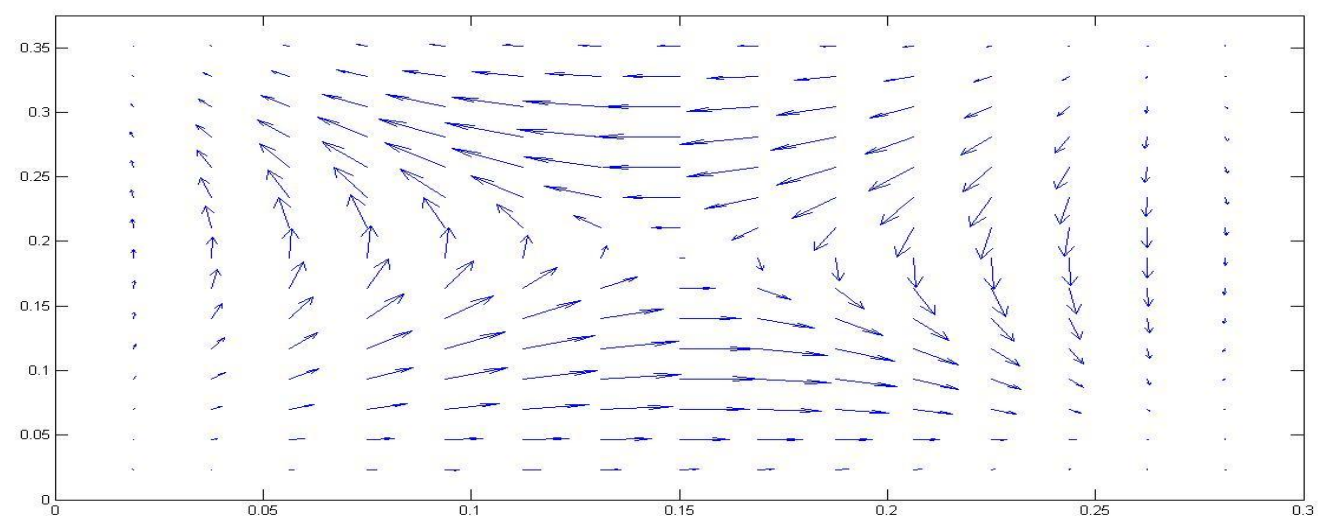

Figure 8. Velocity vectors, in $\mathrm{m} / \mathrm{s}$, of tank without momentum source

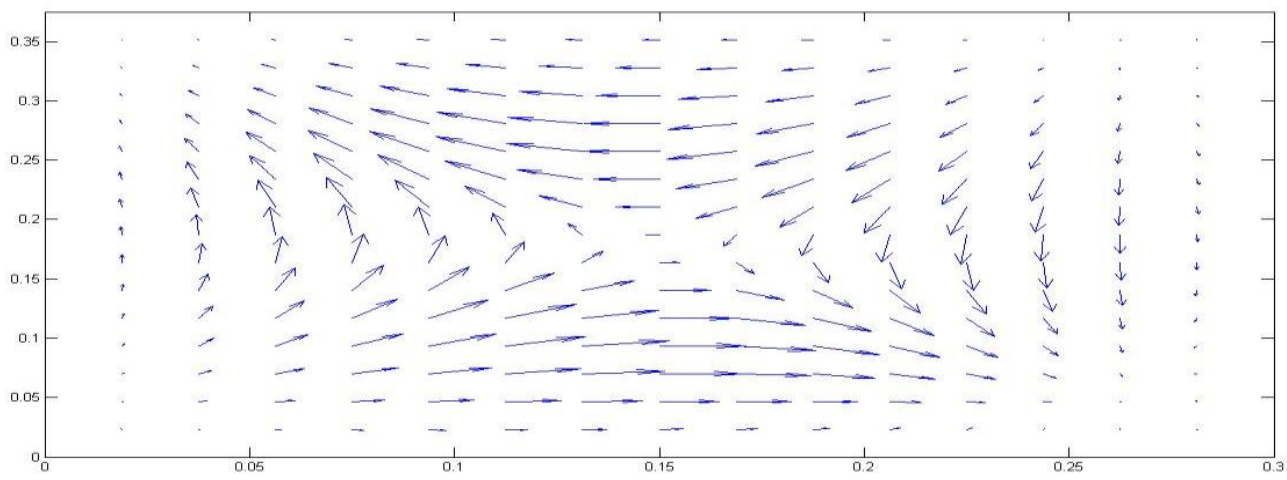

Figure 9. Velocity vectors, in $\mathrm{m} / \mathrm{s}$, of stirred tank at $50 \mathrm{RPM}$

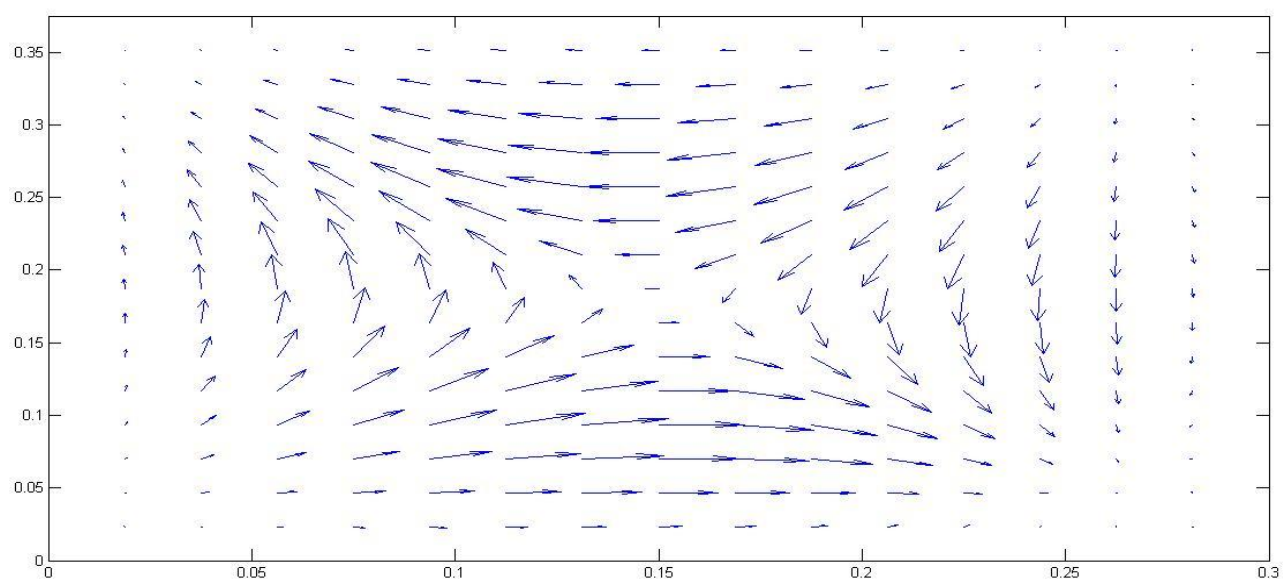

Figure 10. Velocity vectors, in $\mathrm{m} / \mathrm{s}$, of stirred tank at $150 \mathrm{RPM}$ 


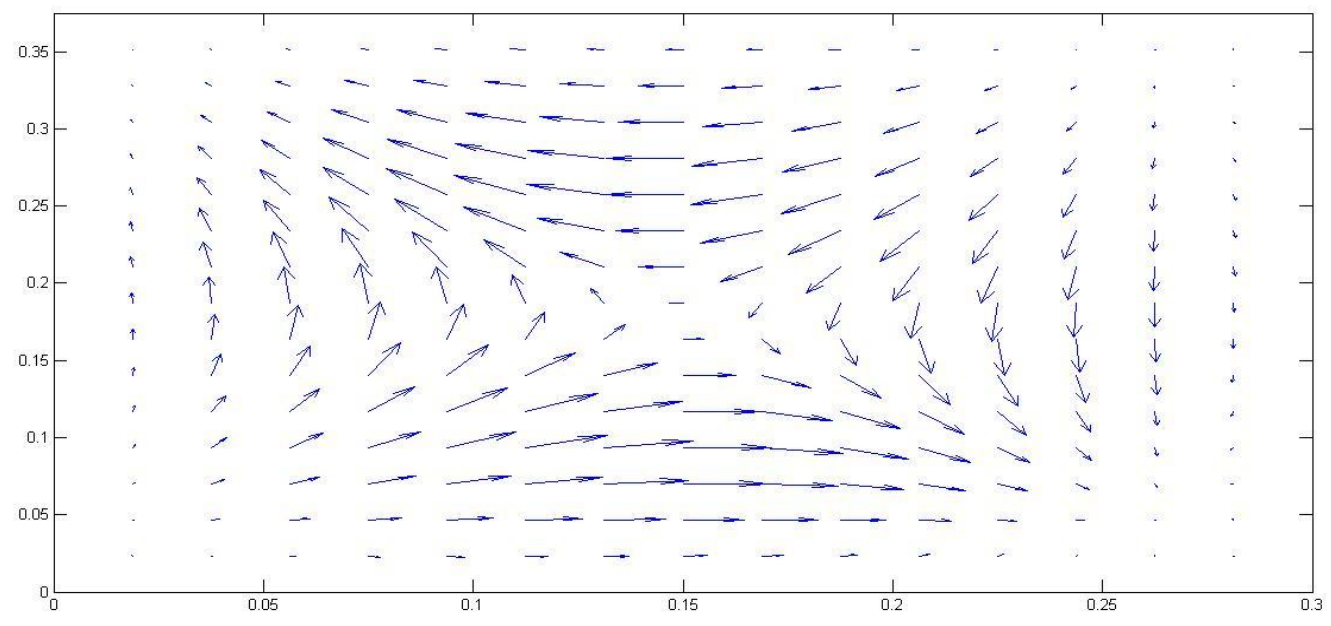

Figure 11. Velocity vectors, in $\mathrm{m} / \mathrm{s}$, of stirred tank at $250 \mathrm{RPM}$

The temperature profile obtained in the homogenizer for all rotational speeds for the time considered can be seen in Fig. 12. A uniform temperature distribution can be observed which represents accurately what the process was intended to achieve. A temperature in the region of $333 \mathrm{~K}$ is maintained throughout the control volume. This shows that the model gives a good picture of the process in the homogenizer.

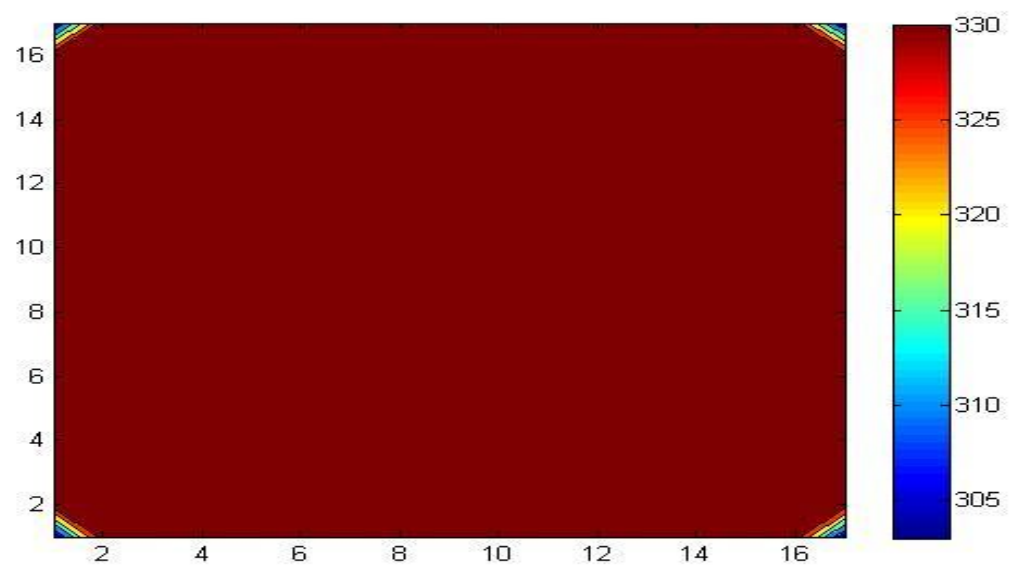

Figure 12. Two dimensional temperature contours, in ${ }^{\circ} \mathrm{K}$, coloured by temperature magnitude for all cases of impeller speed after 40000 iterations.

\section{Conclusions}

A two-dimensional finite volume formulation of a bio-degradable food waste homogenizer is developed. The centrifugal effect of the centered impeller is captured with a non-linear 
distribution of the velocity field within the impeller region. The dynamic behavior of the system at various rotational speeds of the impeller is found to be sensitive to the grid-independent positioning of the stirring region within the computational domain. Preliminary profiles of the fluid velocity and temperature inside the homogenizer are obtained. With additional parametric studies of the impeller configuration, the developed model represents a useful tool in the design of a homogenizer.

\section{References and Notes}

1. Zupančič, G.D.; Viktor, G. "Anaerobic Treatment and Biogas Production from Organic Waste”, In Management of Organic Waste, Kumar D. S., Eds, InTech, 2012.

2. Mata-Alvarez, J.; Macé, S.; Llabrés, P. “Anaerobic digestion of organic solid wastes, An overview of research achievements and perspectives", Bioresource Technology 2000 1, 316.

3. Kubaska, M.; Sedlacek, S.; Bodik, I.; Kissova B. "Food Waste as Biodegradable Substrates for Biogas Production", Institute of Chemical and Environmental Engineering, Slovak University of Technology. Bratislava, Slovak Republic, 2010.

4. Ogedengbe, E.O.B.; Rosen, M.A. "Electro-Kinetic Pumping with Slip Irreversibility in Heat Exchange of CSP-Powered Bio-Digester Assemblies”. Entropy 2012 12, 24392455.

5. Gibson, T.; Smyth, M. "Organic Waste Biodegradability Test Bio Methane Potential Method", Aqua Enviro 2007.

6. Wang, J.Y.; Liu, X.Y.; Kao, J.C.; Stabnikova, O. "Digestion of Pre-treated Food Waste in a Hybrid Anaerobic Solid-liquid (HASL) System”, Journal of Chemical Technology \& Biotechnology 2006 3, 345-351.

7. Harvey, P.S.; Greaves, M. "Turbulent Flow in an Agitated Vessel 2. Numerical-Solution and Model Predictions", Transactions of the Institution of Chemical Engineers 1982.4: 201-210.

8. Luo, J.Y.; Issa R.I.; Gosman, A.D. "Prediction of Impeller-Induced Flows in Mixing Vessels using Multiple Frames of Reference", In 8th Europe Conference of Mixing, Cambridge, UK, 1994. 
9. Mostek, M.; Kukukova, A.; Jahoda, M. "Comparision of different techniques of modelling of flow field and homogenisation in stirred vessels", Chemical Papers 2005. 6A, 380-385.

10. Pericleous, K.A.; Patel, M.K. "The modelling of tangential and axial agitators in chemical reactors", Physico-chimie Chemical Hydrodynamics 1987 8, 105-123.

11. Huang, W.; Li, K. "CFD Simulation of Flows in Stirred Tank Reactors through Prediction of Momentum Source", Nuclear Reactor Thermal Hydraulics and Other Applications, 2013.

12. Patankar, S.V. Numerical Heat Transfer and Fluid Flow, Hemisphere, Washington, DC, 1980.

13. Van Doormaal, J.; Raithby, G.D. "Enhancements of the SIMPLE for predicting incompressible fluid flows", Numerical Heat Transfer 1984, 7, 147-163.

14. Ogedengbe, E.O.B.; Naterer, G.F.; Rosen, M.A. "Slip Flow Irreversibility of Dissipative Kinetic and Internal Energy Exchange in Microchannels", Journal of Micromechanics and Microengineering, 2006, 16, 2167-2176.

15. Abdul, G.A. "A Computer Simulation of Heating and Cooling Liquid Food during Sterilization Process Using Computational Fluid Dynamics", Association for Computing Machinery New Zealand Bulletin, 2006. 